Jurnal Progres Ekonomi Pembangunan (JPEP)

Volume 4, Nomor 2, Tahun 2019

Page: $38-51$

http://ojs.uho.ac.id/index.php/JPEP

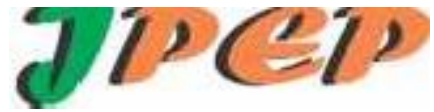

e-ISSN: 2052-5171

\title{
PENGARUH HUMAN CAPITAL DAN SPIRITUAL CAPITAL TERHADAP KUALITAS AUDIT PADA BADAN PEMERIKSA KEUANGAN REPUBLIK INDONESIA PERWAKILAN PROVINSI SULAWESI TENGGARA
}

\author{
Rahmatia Kamba ${ }^{1)}$ \\ Program Ilmu Ekonomi Pascasarjana Universitas Halu Oleo Kendari \\ Email: thyabombana@gmail.com \\ Nasrullah Dali ${ }^{2)}$ \\ Fakultas Ekonomi dan Bisnis Universitas Halu Oleo Kendari \\ Email: nasrullahdali19@gmail.com \\ Mulyati Akib ${ }^{3)}$ \\ Fakultas Ekonomi dan Bisnis Universitas Halu Oleo Kendari \\ Email: mulyatiakib@yahoo.co.id
}

\begin{abstract}
ABSTRAK
Tujuan dari penelitian ini adalah untuk mencari bukti empiris tentang pengaruh human capital dan spiritual capital terhadap kualitas audit. Populasi dalam penelitian ini adalah auditor yang bekerja pada Badan Pemeriksa Keuangan Provinsi Sulawesi Tenggara.Data yang digunakan dalam penelitian ini adalah data primer. Untuk analisis digunakan uji validitas dan reliabilitas sebagai uji instrumen. Penelitian ini menggunakan analisis regresi dan untuk uji hipotesis digunakan uji $\mathrm{F}$ dan uji t. Hasil penelitian menunjukkan bahwa human capital dan spiritual capitalberpengaruh signifikan dan positif terhadap kualitas audit.
\end{abstract}

Kata Kunci : Human Capital, Spiritual Capital, Kualitas Audit

\section{PENDAHULUAN}

Seirama dengan meningkatnya tuntutan masyarakat terhadap penyelenggaraan pemerintahan yang baik saat ini, mendorong pemerintah daerah untuk menerapkan akuntabilitas publik sebagai bentuk kewajiban mempertanggungjawabkan keberhasilan atau kegagalan pelaksanaan misi organisasi melalui suatu media pertanggungjawaban yang dilaksanakan secara periodik (Mardiasmo: 2006) dalam mewujudkan transparansi dan akuntabilitas publik guna mencapai good governance.

Laporan keuangan yang komprehensif sebagai bentuk pertanggungjawaban harus diperiksa oleh Badan Pemeriksa Keuangan (BPK). BPK diberikan mandat oleh UUD 1945 untuk memeriksa pengelolaan dan tanggung jawab keuangan negara secara bebas dan mandiri yang artinya BPK memiliki kebebasan dan kemandirian dalam perencanaan, pelaksanaan, pelaporan, dan pemantauan tindak lanjut hasil pemeriksaan.

Peningkatan kualitas laporan keuangan pemerintah daerah juga dapat dilihat dari peningkatan opini hasil pemeriksaan BPK terhadap Laporan Keuangan Pemerintah Daerah (LKPD). Laporan Keuangan Pemerintah Daerah yang terus mengalami peningkatan perolehan opini WTP salah satunya ialah Provinsi Sulawesi Tenggara dimana pada tahun 2013 opini WTP hanya diperoleh oleh Pemerintah Provinsi Sulawesi Tenggara namun dalam rentang waktu 5 tahun, 14 kabupatennya telah memperoleh opini audit WTP di tahun 2017. Hasil pemeriksaan LKPD kabupaten/kota di Provinsi Sulawesi Tenggara yang konsisten memperoleh opini WTP selama 4 tahun sejak tahun 2014 hingga 2017 yaitu Kabupaten Bombana, Kabupaten Buton, Kabupaten Kolaka Utara, Kabupaten Wakatobi, dan Kota Kendari. Sedangkan Provinsi Sulawesi Tenggara konsisten memperoleh opini WTP selama 5 tahun sejak tahun 2013 hingga 2017.

Pemeriksaan oleh BPK RI tidak hanya menghasilkan opini atas laporan keuangan yang diaudit tetapi juga memberikan catatan hasil temuan.Temuan tersebut menjelaskan kelemahan pengendalian internal dan ketidaktaatan terhadap peraturan perundang undangan. Hasil audit juga memberikan informasi potensi kerugian negara yang ditemukan dalam proses pemeriksaan akibat dari penyalahgunaan dan 
Jurnal Progres Ekonomi Pembangunan (JPEP)

Volume 4, Nomor 2, Tahun 2019

Page: $38-51$

http://ojs.uho.ac.id/index.php/JPEP

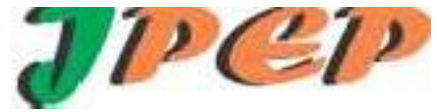

e-ISSN: 2052-5171

inefisiensi penggunaan APBN/APBD. Beberapa hasil audit BPK RI tersebut ditindaklanjuti menjadi audit investigasi, kasus korupsi, dan kasus pidana. Menurut standar pengauditan, faktor yang membedakan kecurangan dan kekeliruan adalah apakah tindakan yang mendasarinya, yang berakibat terjadinya salah saji dalam laporan keuangan, berupa tindakan yang sengaja atau tidak disengaja (IAI: 2001).

Pemerintah daerah di Sulawesi Tenggara mayoritas sudah memperoleh opini WTP secara konsisten dalam beberapa tahun terakhir.Namun masih ada beberapa kabupaten yang memperoleh opini WDP. Sementara di sisi lain pemerintah daerah dituntut untuk mampu mengelola keuangan secara transparan dan akuntabel guna mencapai good governance. Selain itu, peningkatan kualitas audit melalui berbagai cara pun perlu dilakukan, seperti penguasaan IT audit dalam laporan keuangan (Siaran Pers BPK, 2019) agar tidak terjadi suatu hal yang tidak diinginkan seperti adanya opini palsu atau tidak sesuai dengan hasil audit laporan keuangan seharusnya. Dari fenomena opini LKPD tersebut dan pernyataan dari BPK sendiri terkait opini WTP bukan jaminan suatu entitas bebas korupsi, menjadi topik yang menarik untuk diteliti mengenai faktor-faktor apa saja yang mempengaruhi kualitas audit BPK.

Kualitas audit menurut De Angelo (1981) didefinisikan sebagai kemungkinan auditor akan menemukan dan melaporkan pelanggaran dalam sistem akuntansi klien. Kualitas audit dipengaruhi oleh berbagai faktor dalam setiap tahapannya. Hal itu dapat terjadi pada proses audit, baik dari tahapantahapan perencanaan audit, pelaksanaan audit, dan pelaporan hasil pelaksanaan audit hingga tindak lanjut hasil audit.

Salah satu faktor yang mempengaruhi kualitas audit adalah human capital (HC). Naslmosavi et al (2013) menyatakan human capital berhubungan dengan pengetahuan tiap personal yang didalamnya termasuk kemampuan, pengalaman, nilai, aset berfikir, pengetahuan, dan kemampuan tiap individu yang dibutuhkan untuk menyediakan solusi bagi pelanggan. Auditor dengan human capital yang baik akan dapat menemukan kesalahan pada laporan keuangan, sehingga laporan keuangan tersebut terhindar dari salah yang material dan memberikan hasil audit yang berkualitas tinggi dan dapat dimanfaatkan oleh pihak-pihak terkait.

Ismail (2005) spiritual capital merupakan sumber utama dari semua sumber modal pengetahuan karena berhubungan langsung dengan pikiran, emosi dan keyakinan kepada Tuhan. Naslmosavi et al (2017) spiritual capital (SpC) adalah gabungan antara moral, etika, nilai-nilai pribadi dan budaya yang dianut, untuk dapat mengerjakan suatu pekerjaan, memecahkan suatu masalah, dan mengambil keputusan yang penting. Auditor dengan spiritual capital yang baik akan mampu menyelesaikan pekerjaan audit dengan baik sesuai dengan aturan yang berlaku dan etika profesi, mengutamakan kejujuran dalam pekerjaan, dan tidak mudah untuk melakukan kecurangan.

Berdasarkan uraian latar belakang di atas dan berbagai fenomena serta kesenjangan penelitian terdahulu yang telah dijelaskan sebelumnya, peneliti tertarik memahami bagaimana kualitas pemeriksaan keuangan BPK RI sehingga peneliti akan melakukan penelitian dengan judul "Pengaruh Human Capital dan Spiritual Capital terhadap Kualitas Audit Pada BPK RI Perwakilan Provinsi Sulawesi Tenggara".

\section{Rumusan Masalah}

Berdasarkan latar belakang, maka perumusan masalah dalam penelitian ini adalah:

1. Apakahhuman capital berpengaruh signifikan terhadap kualitas audit padaBPK RI Perwakilan Provinsi Sulawesi Tenggara?

2. Apakahspiritual capital berpengaruh signifikan terhadap kualitas audit pada BPK RI Perwakilan Provinsi Sulawesi Tenggara?

\section{Tujuan Penelitian}

Berdasarkan rumusan masalah penelitian yang telah disebutkan sebelumnya, tujuan penelitian ini adalah untuk mencari bukti empiris tentang pengaruh karakteristik pribadi auditor terhadap kualitas audit, dengan perincian berikut:

1. Untuk mengetahui dan menganalisis pengaruh human capital terhadap kualitas audit pada BPK RI Perwakilan Provinsi Sulawesi Tenggara.

2. Untuk mengetahui dan menganalisis pengaruh spiritual capital terhadap kualitas audit pada BPK RI Perwakilan Provinsi Sulawesi Tenggara. 
Jurnal Progres Ekonomi Pembangunan (JPEP)

Volume 4, Nomor 2, Tahun 2019

Page: $38-51$

http://ojs.uho.ac.id/index.php/JPEP

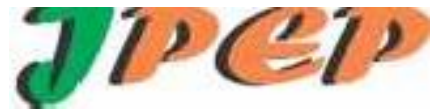

e-ISSN: 2052-5171

\section{TINJAUAN PUSTAKA DAN PENGEMBANGAN HIPOTESIS}

Teori agensi dalam konteks pemerintahan, dipandang dalam perspektif bahwa pemerintah daerah adalah agent bagi publik atau masyarakat, sehingga dalam hal ini masyarakat atau publik diposisikan sebagai principal. Pelaksanaan berbagai tugas pemerintah merupakan bentuk nyata dari pelaksanaan tugas dan kewenangan yang dimiliki berdasarkan legitimasi dari publik, namun dalam pelaksanaannya sering terjadi ketidakseimbangan informasi antara agent (pemerintah) yang mempunyai akses langsung terhadap informasi dengan pihak principal (masyarakat). Adanya informasi yang asimetri inilah yang menjadikan para agent berlaku oportunis atas peluang yang ada dan dapat mengarah pada terjadinya kecurangan (fraud) serta penyelewengan.

Konflik keagenan juga memiliki peran sebagai penggerak kualitas audit. Di dalam teori keagenan disampaikan bahwa fungsi pengauditan adalah salah satu mekanisme untuk mengurangi konflik keagenan antara agent denganprincipal.Khususnya, mekanisme yang meningkatkan kemungkinan auditor akan melaporkan pelanggaran dalam kontrak yang akan dipantau, mekanisme yang dirancang yang memberikan insentif bagi auditor untuk mempertahankan independensi mereka pada principal dan agent (Zimmerman \& Watts : 1983).Masyarakat (principal) memiliki kebutuhan atas profesi auditor yaitu auditor's independent sebagai pihak penengah dalam menangani konflik keagenan. Auditor dianggap sebagai pihak yang independen antara pemerintah (agent) sebagai penyedia informasi (laporan keuangan) dan para stakeholders sebagai pengguna informasi, sehingga mengurangi ketidaksimetrisan informasi (asymetry information) antara kedua belah pihak. Semakin besar konflik keagenan, semakin tinggi biaya keagenan, dan semakin tinggi permintaan untuk auditor yang berkualitas (Tandiontong, 2015).

De Angelo (1981) dalam Bouhawia (2015) mengatakan bahwa kualitas audit adalah kombinasi probabilitas dari auditor yang kompeten untuk menemukan pelanggaran dalam sistem akuntansi klien dan untuk melaporkan temuan mereka secara independen. Boynton et al (2006) berpendapat bahwa setiap profesi secara konsisten terkait dengan kualitas layanan yang diberikannya, termasuk auditor di mana kualitas layanannya sangat penting untuk memastikan bahwa profesi ini bertanggung jawab kepada klien, orang-orang, dan peraturan.Kualitas audit mengacu pada standar mengenai kriteria atau ukuran kualitas pelaksanaan dan juga terkait untuk tujuan yang ingin dicapai dengan menerapkan prosedur terkait.

Bontis et al (2000) menyatakan human capital adalah kombinasi dari pengetahuan, skill, kemampuan melakukan inovasi, dan kemampuan menyelesaikan tugas, meliputi nilai perusahaan, kultur dan filsafatnya. Jika perusahaan berhasil dalam mengelola pengetahuan karyawannya, maka hal itu dapat meningkatkan human capital. Sehingga human capital merupakan kekayaan yang dimiliki oleh suatu perusahaan yang terdapat dalam tiap individu atau dengan kata lain adalah sumber daya manusia yang ada di dalamnya.

Ismail (2005) dalam penelitiannya menyatakan human capital adalah asset pemikiran, hal tersebut merupakan pengetahuan, keterampilan, dan kemampuan karyawan individu untuk memberikan solusi terhadap pelanggan, human capital merupakan pengetahuan individu dari sebuah organisasi dan human capital adalah kemampuan kolektif perusahaan untuk mengesktrak solusi terbaik dari pengetahuan individu.

Mohtar et al (2015) menyatakan bahwa spiritual capital ( $\mathrm{SpC}$ ) adalah komponen yang penting bagi intellectual capital (IC). Menurut Berger dan Helfiner (2003) menyatakan bahwa spiritual capital adalah kombinasi dari kekuatan, pengaruh, semangat dan pengetahuan yang dapat diperoleh melalui agama. Ismail (2005) menyatakan bahwa spiritual capital sebagai komponen tambahan intellectual capital.Selain itu, ia juga mengatakan, spiritual capital adalah "pengetahuan tak berwujud, iman dan emosi yang tertanam di benak individu dan di jantung organisasi yang mencakup visi, arah, bimbingan, prinsip, nilai, dan budaya". Desain bawaan dari manusia atau hakekat manusia tampaknya tidak hanya berdiam dianatomi dan fisiologi, tetapi juga terletak pada kebutuhan dasar dan kapasitas psikologis. Hakekat ini tidak jelas dan tidak dapat dilihat, tetapi tersembunyi (Ismail: 2005). Dalam penelitian Ismail (2005) terdapat definisi spiritual capital menurut beberapa pendapat: (a). Spiritualitas sebagai "kepercayaan dalam tindakan" atau "hal yang menghubungkan kepercayaan dengan tindakan". (b). Spiritualitas mencerminkan keinginan untuk tahu tentang pengalaman dan entitas kosmik yang tidak mudah ditangkap 
Jurnal Progres Ekonomi Pembangunan (JPEP)

Volume 4, Nomor 2, Tahun 2019

Page: $38-51$

http://ojs.uho.ac.id/index.php/JPEP

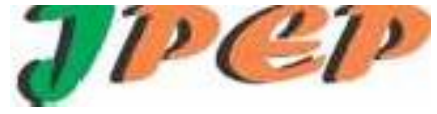

e-ISSN: 2052-5171

dalam pengertian materi tapi tetap saja, tampaknya penting untuk manusia. Selain itu, spiritual juga mengacu pada segala sesuatu - pikiran, tubuh, diri, alam, dan supranatural dan kadang-kadang, bahkan tidak ada.

\section{Kerangka Konsep Dan Hipotesis}

Kerangka konsep variabel penelitian dibuat berdasarkan hasil penggabungan variabel independen dan variabel dependen.Dalam penelitian ini, yang menjadi variabel independen adalah human capital dan spiritual capital. Sedangkan yang menjadi variabel dependen adalah kualitas audit. Sehingga dapat digambarkan kerangka konsep variabel penelitian sebagai berikut:

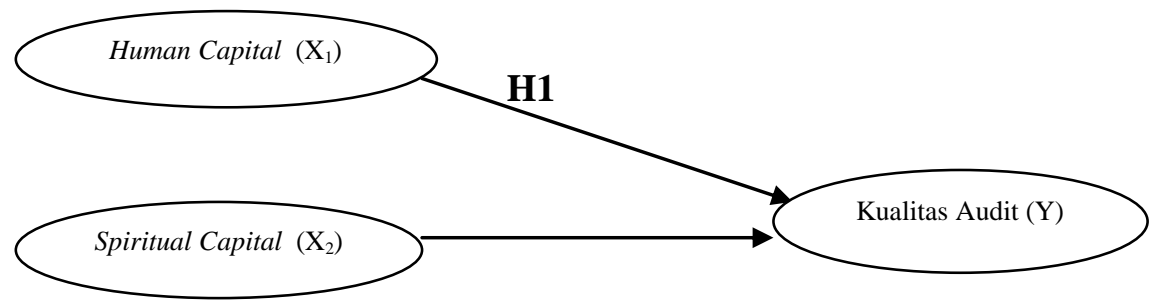

Gambar 2.1. Kerangka Konsep Penelitian

Human capital yang didukung kompetensi yang baik, pengetahuan dan keahlian akan teknik audit, pengalaman dalam mengidentifikasi kesalahan dalam laporan klien, komitmen yang kuat terhadap pencapaian tujuan organisasi saat menemui hambatan dan kendala yang kesemuanya itu akan bermuara pada peningkatan kualitas audit yang dilakukan oleh auditor. Hasil penelitian Cheng et al (2009), Riswan (2012), Simorangkir (2012), dan Bouhawia (2015), mempunyai bukti yang sama bahwa human capital secara simultan berpengaruh positif terhadap kualitas audit seorang auditor. Semakin tinggi tingkat human capital maka kualitas audit yang dihasilkan pun akan semakin baik. Oleh karena itu, peneliti mengemukakan hipotesis sebagai berikut:

H1: Human capitalberpengaruh signifikan terhadap kualitas audit.

Spiritual capital harus dimiliki oleh setiap auditor karena pekerjaan audit harus berpegang teguh terhadap kejujuran dan etika profesi agar tidak melanggar aturan yang telah ditetapkan.

Hasil penelitian Ismail (2005), Januraga (2015) dan Naslmosavi (2013) membuktikan bahwa spiritual capital berpengaruh positif signifikan terhadap kualitas audit seorang auditor. Semakin tinggi tingkat spiritual capital maka kualitas audit yang dihasilkan pun akan semakin baik. Oleh karena itu, peneliti mengemukakan hipotesis sebagai berikut:

H2 :Spiritual capital berpengaruh signifikan terhadap kualitas audit.

\section{METODE PENELITIAN}

\section{Jenis Penelitian}

Jenis penelitian yang digunakan dalam penelitian ini adalah penelitian asosiatif yang bertujuan untuk mengetahui pengaruh atau hubungan antara dua atau lebih variabel (Sugiyono, 2017: 61).

\section{Lokasi dan Waktu Penelitian}

Badan Pemeriksa Keuangan Republik Indonesia (BPK RI) Perwakilan Provinsi Sulawesi Tenggara yang berlokasi di Kota Kendari.

\section{Definisi Operasional Variabel}

Dalam penelitian ini definisi operasional yang digunakan adalah sebagai berikut:

1. Kualitas audit merupakan probabilitas dimana seorang auditor menemukan dan melaporkan tentang adanya suatu pelanggaran dalam sistem akuntansi kliennya (DeAngelo: 1981). 
Jurnal Progres Ekonomi Pembangunan (JPEP)

Volume 4, Nomor 2, Tahun 2019

Page: $38-51$

http://ojs.uho.ac.id/index.php/JPEP

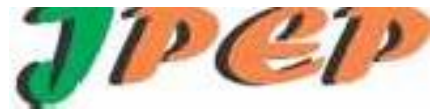

e-ISSN: 2052-5171

2. Human capital (HC) merupakan gabungan dari pengetahuan, pengalaman, kompetensi dan komitmen yang dimiliki oleh auditor BPK RI Perwakilan Provinsi Sulawesi Tenggara yang dapat meningkatkan kualitas pekerjaannya atau menciptakan sebuah inovasi yang baru.

3. Spiritual capital $(\mathrm{SpC})$ adalah gabungan antara moral, etika dan budaya yang dianut, untuk dapat mengerjakan suatu pekerjaan, memecahkan suatu masalah, dan mengambil keputusan yang penting.

\section{Metode Analisis Data}

Alat analisis yang digunakan adalah analisis regresi. Analisis regresi linier berganda digunakan untuk mengetahui ketergantungan variabel dependen (terikat) dengan satu atau lebih variabel independen (variabel penjelas/bebas) dengan tujuan untuk mengestimasi dan/ atau memprediksi rata-rata populasi atau nilai rata-rata variabel dependen berdasarkan nilai variabel independen yang diketahui (Ghozali, 2018: 95). Dalam menganalisis data penelitian digunakan software SPSS (Statistical Program for Social Science) versi 23. Metode yang digunakan yaitu analisis deskriptif, uji asumsi klasik, uji signifikansi parameter individual (uji t) dan koefisien determinasi R2

\section{Analisis Deskriptif}

Statistik deskriptif adalah statistik yang digunakan untuk menganalisis data dengan cara mendeskripsikan atau menggambarkan data yang telah terkumpul sebagaimana adanya tanpa bermaksud membuat kesimpulan yang berlaku untuk umum atau generalisasi, seperti penyajian data melalui tabel, grafik, diagram lingkaran (piechart), perhitungan penyebaran data melalui perhitungan rata-rata dan presentase (Sugiyono, 2017: 199-200).

\section{Analsis Regresi Linear Berganda}

Pengujian hipotesis penelitian dilakukan dengan menggunakan model analisis regresi linear berganda. Analisis regresi linear berganda digunakan untuk mengetahui ketergantungan variabel dependen (terikat) dengan satu atau lebih variabel independen (variabel penjelas/bebas) dengan tujuan untuk mengestimasi dan/ atau memprediksi rata-rata populasi atau nilai rata-rata variabel dependen berdasarkan nilai variabel independen yang diketahui (Ghozali, 2018: 95) yaitu pengaruh human capital dan spiritual capital terhadap kualitas audit.

Persamaan regresinya adalah sebagai berikut:

$\mathbf{Y}=\mathbf{a}+\mathbf{b}_{1} \mathbf{X}_{1}+\mathbf{b}_{2} \mathbf{X}_{2}+\mathbf{e} \ldots \ldots \ldots \ldots$

Dimana :

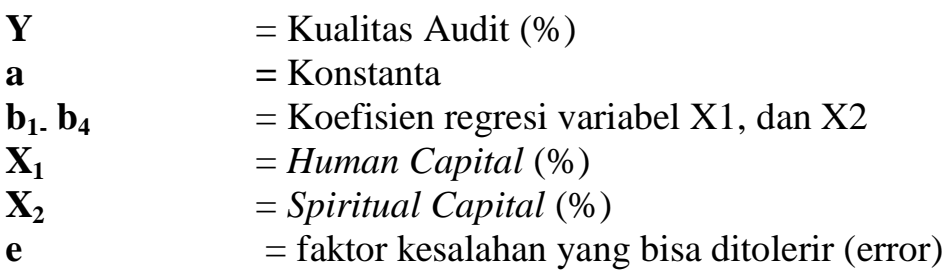

\section{Analisis Koefisien Determinasi $\left(\mathbf{R}^{2}\right)$}

Uji koefisien determinasi dilakukan untuk mengetahui seberapa besar variabel independen dapat menjelaskan variabel dependen. Dianjurkan untuk menggunakan nilai adjusted $R$-Squares dalam mengevaluasi model regresi, dimana nilainya dapat naik atau turun apabila satu variabel independen ditambahkan kedalam model.

\section{Uji Signifikasi Simultan (Uji Statistik F)}

Uji $\mathrm{F}$ bertujuan untuk mengetahui apakah semua variabel independen yang dimasukkan dalam model regresi mempunyai pengaruh simultan (bersama-sama) terhadap variabel dependen ataukah tidak. Cara untuk menguji yaitu dapat dilakukan dengan membandingkan $\mathrm{F}_{\text {hitung }}$ dengan $\mathrm{F}_{\text {tabel }}$ dan nilai $\mathrm{t}$-sig dengan $\alpha: 0,05$. Apabila $F_{\text {hitung }}>F_{\text {tabel }} F$-sig $<$ dari $\alpha: 0,05$, maka maka dapat disimpulkan bahwa semua variabel independen secara simultan berpengaruh signifikan terhadap variabel dependen.

\section{Uji Signifikan Parameter Individual (Uji t)}

Uji t digunakan untuk mengetahui pengaruh variabel-variabel $\mathrm{X}$ terhadap variabel Y. Uji $\mathrm{t}$ dapat dilakukan dengan membandingkan antara $t_{\text {hitung }}$ dengan $t_{\text {tabel }}$ dan nilai $t$-sig dengan $\alpha: 0,05$. Apabila $t_{\text {hitung }}$ 
Jurnal Progres Ekonomi Pembangunan (JPEP)

Volume 4, Nomor 2, Tahun 2019

Page: $38-51$

http://ojs.uho.ac.id/index.php/JPEP

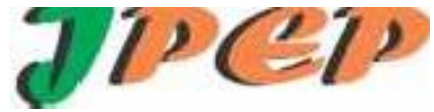

e-ISSN: 2052-5171

$>\mathrm{t}_{\text {tabel }} \mathrm{t}$-sig $<$ dari $\alpha$ : 0,05, maka diterima H1 atau tolak H0. Sebaliknya, apabila $\mathrm{t}_{\text {hitung }}<\mathrm{t}_{\text {tabel }} \mathrm{t}$-sig $>$ dari $\alpha$ : 0,05 maka tolak $\mathrm{H} 1$ atau terima $\mathrm{H} 0$.

\section{HASIL PENELITIAN DAN PEMBAHASAN}

\section{Hasil Penelitian}

\section{Gambaran Umum Objek Penelitian}

Struktur organisasi BPK RI Perwakilan Provinsi Sulawesi Tenggara ditetapkan dalam Peraturan BPK RI No. 1 Tahun 2019 tentang Organisasi dan Tata Kerja Pelaksana Badan Pemeriksa Keuangan. BPK RI Perwakilan Provinsi Sulawesi Tenggara berada di bawah AKN VI dan bertanggung jawab kepada Anggota VI BPK melalui Auditor Utama Keuangan Negara VI. BPK RI Perwakilan Provinsi Sulawesi Tenggara dipimpin oleh seorang kepala. BPK RI Perwakilan Provinsi Sulawesi Tenggara terdiri atas: Sekretariat Perwakilan; Sub auditorat Sulawesi Tenggara I; Sub auditorat Sulawesi Tenggara II; dan Kelompok Jabatan Fungsional.

Sub auditorat Sulawesi Tenggara I mempunyai tugas: pada lingkup Pemerintah Provinsi Sulawesi Tenggara, Kota Kendari, Kabupaten Konawe, Kabupaten Kolaka, Kabupaten Kolaka Utara, Kabupaten Kolaka Timur, Kabupaten Konawe Utara, Kabupaten Konawe Kepulauan, BUMD, dan lembaga terkait di lingkungan entitas. Sedangkan Sub auditorat Sulawesi Tenggara II mempunyai tugas: pada lingkup Pemerintah Kota Bau-Bau, Kabupaten Buton, Kabupaten Wakatobi, Kabupaten Muna, Kabupaten Konawe Selatan, Kabupaten Bombana, Kabupaten Buton Utara, Kabupaten Muna Barat, Kabupaten Buton Tengah, Kabupaten Buton Selatan, BUMD, dan lembaga terkait di lingkungan entitas, dimana masing-masing sub auditorat tersebut membawahi para pemeriksa (auditor).

\section{Hasil Uji Kualitas Data}

Hasil Uji Validitas dan Realibiltas Data

Berdasarkan Tabel 4.1 menunjukkan bahwa hasil uji validitas variabel human capital, spiritualcapital dan kualitas audit yang terdiri atas 35(tiga puluh lima) butir pernyataan adalah valid, dimana nilai $r_{\text {hitung }}>$ nilai $r_{\text {tabel }}$ dan memiliki nilai signifikansi lebih kecil dari 0,05 . Hal ini berarti bahwa semua butir pernyataan dalam penelitian ini layak digunakan. Berdasarkan tabel 4.1 menunjukkan bahwa hasil perhitungan nilai Cronbach's Alpha untuk setiap variabel adalah lebih besar dari 0,70. Dengan demikian, dapat disimpulkan bahwa pernyataan untuk masing -masing variabel dikatakan reliabel.

Tabel 4.1 Hasil Uji Validitas dan Realibilitas

\begin{tabular}{|c|c|c|c|c|c|c|c|}
\hline Variabel & Pernyataan & $r_{\text {hitung }}$ & $r_{t a b e l}$ & Signifikansi & Kriteria & $\begin{array}{c}\text { Cronbach } \\
\text { Alpha }\end{array}$ & Keterangan \\
\hline \multirow{11}{*}{$\begin{array}{c}\text { Human } \\
\text { Capital } \\
\left(\mathrm{X}_{1}\right)\end{array}$} & $\mathrm{X}_{1.1 .1}$ & 0,804 & 0,2521 & 0,000 & Valid & \multirow{11}{*}{0,760} & \multirow{11}{*}{ Reliabel } \\
\hline & $\mathrm{X}_{1.1 .2}$ & 0,663 & 0,2521 & 0,000 & Valid & & \\
\hline & $\mathrm{X}_{1.1 .3}$ & 0,668 & 0,2521 & 0,000 & Valid & & \\
\hline & $\mathrm{X}_{1.2 .1}$ & 0,685 & 0,2521 & 0,000 & Valid & & \\
\hline & $\mathrm{X}_{1.2 .2}$ & 0,664 & 0,2521 & 0,000 & Valid & & \\
\hline & $\mathrm{X}_{1.2 .2 .3}$ & 0,614 & 0,2521 & 0,000 & Valid & & \\
\hline & $\mathrm{X}_{1.2 .4}$ & 0,683 & 0,2521 & 0,000 & Valid & & \\
\hline & $\mathrm{X}_{1.3 .1}$ & 0,623 & 0,2521 & 0,000 & Valid & & \\
\hline & $\mathrm{X}_{1.3 .2}$ & 0,671 & 0,2521 & 0,000 & Valid & & \\
\hline & $\mathrm{X}_{1.3 .3}$ & 0,590 & 0,2521 & 0,000 & Valid & & \\
\hline & $\mathrm{X}_{1.3 .4}$ & 0,592 & 0,2521 & 0,000 & Valid & & \\
\hline Spiritual & $X_{2.1 .1}$ & 0,663 & 0,2521 & 0,000 & Valid & 0,767 & Reliabel \\
\hline
\end{tabular}


Jurnal Progres Ekonomi Pembangunan (JPEP)

Volume 4, Nomor 2, Tahun 2019

Page: $38-51$

http://ojs.uho.ac.id/index.php/JPEP

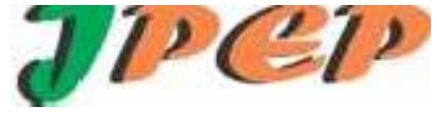

e-ISSN: 2052-5171

\begin{tabular}{|c|c|c|c|c|c|c|c|}
\hline \multirow{10}{*}{$\begin{array}{c}\text { Capital } \\
\left(\mathrm{X}_{2}\right)\end{array}$} & $X_{2.1 .2}$ & 0,681 & 0,2521 & 0,000 & Valid & & \\
\hline & $\mathrm{X}_{2.2 .1}$ & 0,647 & 0,2521 & 0,000 & Valid & & \\
\hline & $\mathrm{X}_{2.2 .2}$ & 0,700 & 0,2521 & 0,000 & Valid & & \\
\hline & $\mathrm{X}_{2.3 .1}$ & 0,775 & 0,2521 & 0,000 & Valid & & \\
\hline & $\mathrm{X}_{2.3 .2}$ & 0,660 & 0,2521 & 0,000 & Valid & & \\
\hline & $\mathrm{X}_{2.3 .3}$ & 0,706 & 0,2521 & 0,000 & Valid & & \\
\hline & $X_{2.4 .1}$ & 0,692 & 0,2521 & 0,000 & Valid & & \\
\hline & $\mathrm{X}_{2.4 .2}$ & 0,667 & 0,2521 & 0,000 & Valid & & \\
\hline & $\mathrm{X}_{2.5 .1}$ & 0,644 & 0,2521 & 0,000 & Valid & & \\
\hline & $\mathrm{X}_{2.5 .2}$ & 0,613 & 0,2521 & 0,000 & Valid & & \\
\hline \multirow{13}{*}{$\begin{array}{c}\text { Kualitas } \\
\text { Audit } \\
\text { (Y) }\end{array}$} & $Y_{1.1 .1}$ & 0,590 & 0,2521 & 0,000 & Valid & \multirow{13}{*}{0.755} & \multirow{13}{*}{ Reliabel } \\
\hline & $Y_{1.1 .2}$ & 0,634 & 0,2521 & 0,000 & Valid & & \\
\hline & $Y_{1.2 .1}$ & 0,604 & 0,2521 & 0,000 & Valid & & \\
\hline & $Y_{1.2 .2}$ & 0,607 & 0,2521 & 0,000 & Valid & & \\
\hline & $\mathrm{Y}_{1.2 .3}$ & 0,668 & 0,2521 & 0,000 & Valid & & \\
\hline & $\mathrm{Y}_{1.3 .1}$ & 0,614 & 0,2521 & 0,000 & Valid & & \\
\hline & $\mathrm{Y}_{1.3 .2}$ & 0,678 & 0,2521 & 0,000 & Valid & & \\
\hline & $\mathrm{Y}_{1.4 .1}$ & 0,675 & 0,2521 & 0,000 & Valid & & \\
\hline & $\mathrm{Y}_{1.4 .2}$ & 0,618 & 0,2521 & 0,000 & Valid & & \\
\hline & $\mathrm{Y}_{1.5 .1}$ & 0,622 & 0,2521 & 0,000 & Valid & & \\
\hline & $Y_{1.5 .2}$ & 0,602 & 0,2521 & 0,000 & Valid & & \\
\hline & $Y_{1.6 .1}$ & 0,654 & 0,2521 & 0,000 & Valid & & \\
\hline & $Y_{1.6 .2}$ & 0,669 & 0,2521 & 0,000 & Valid & & \\
\hline
\end{tabular}

Sumber: Data Primer Diolah, 2019

\section{Analisis Regresi Linear Berganda}

Analisis yang digunakan untuk menguji hipotesis dalam penelitian ini adalah regresi linear berganda (multivariat). Analisis regresi linear berganda digunakan untuk mengetahui pengaruh antara variabel independen terhadap variabel dependen. Pengujian hipotesis dapat dilakukan dengan membandingkan $t_{\text {hitung }}$ dengan $t_{\text {tabel }}$ dan nilai $t$-sig dengan $\alpha: 0,05$. Apabila $t_{\text {hitung }}>t_{\text {tabel }} t$-sig $<$ dari $\alpha$ : 0,05 , maka diterima $\mathrm{H} 1$ atau tolak H0. Sebaliknya, apabila $\mathrm{t}_{\text {hitung }}<\mathrm{t}_{\text {tabel }} \mathrm{t}$-sig $>$ dari $\alpha: 0,05$ maka tolak H1 atau terima H0. Hasil uji regresi linear berganda dalam penelitian ini disajikan dalam bentuk tabel sebagai berikut:

Tabel 4.2. Hasil Uji Regresi Linear Berganda

\begin{tabular}{|c|c|c|c|c|c|}
\hline \multirow[b]{2}{*}{ Model } & \multicolumn{2}{|c|}{$\begin{array}{l}\text { Unstandardized } \\
\text { Coefficients }\end{array}$} & \multicolumn{3}{|l|}{$\begin{array}{l}\text { Standardized } \\
\text { Coefficients }\end{array}$} \\
\hline & B & Std. Error & Beta & $\mathrm{t}$ & Sig. \\
\hline $1 \quad$ (Constant) & 17.098 & 4.508 & & 3.792 & .000 \\
\hline $\mathrm{X} 1$ & .335 & .098 & .348 & 3.398 & .001 \\
\hline $\mathrm{X} 2$ & .456 & .094 & .496 & 4.842 & .000 \\
\hline
\end{tabular}

Sumber: Data Primer Diolah, 2019

Berdasarkan hasil analisis regresi berganda pada Tabel 4.2 diperoleh nilai koefisien regresi masingmasing variabel, sehingga dapat dibuat suatu persamaan regresi sebagai berikut: 
Jurnal Progres Ekonomi Pembangunan (JPEP)

Volume 4, Nomor 2, Tahun 2019

Page: $38-51$

http://ojs.uho.ac.id/index.php/JPEP

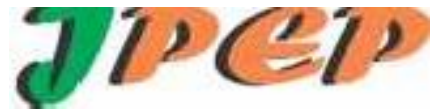

e-ISSN: 2052-5171

$$
\mathrm{Y}=17,098+0,335 \mathrm{X} 1+0,456 \mathrm{X} 2+\mathrm{e}
$$

Sehingga hasil regresi linear berganda dapat dijabarkan sebagai berikut:

1. Persamaan regresi linear berganda diatas menunjukkan bahwa nilai konstanta $(\alpha)$ sebesar 17,098 . Hal ini berarti bahwa jika variabel bebas yaitu human capital $\left(\mathrm{X}_{1}\right)$, dan spiritual capital $\left(\mathrm{X}_{2}\right)$ memiliki nilai sama dengan nol, maka perubahan kualitas audit (Y) akan konstan sebesar 17,098 satuan.

2. Koefisien regresi untuk variabel human capital adalah sebesar 0,335. Hal ini berarti bahwa terdapat hubungan yang positif antara human capital terhadap kualitas audit, sehingga dapat diartikan bahwa apabila variabel human capital terjadi kenaikan 1 satuan dan variabel lainnya diasumsikan konstan, maka kualitas audit akan mengalami peningkatan sebesar 0,335 satuan.

3. Koefisien regresi untuk variabel spiritual capital adalah sebesar 0,456. Hal ini berarti bahwa terdapat hubungan yang positif antara spiritual capital terhadap kualitas audit, sehingga dapat diartikan bahwa apabila variabel spiritual capital terjadi kenaikan 1 satuan dan variabel lainnya diasumsikan konstan, maka kualitas audit akan mengalami peningkatan sebesar 0,456 satuan.

\section{Hasil Uji Koefisien Determinasi}

Hasil uji koefisien determinasi dilakukan untuk mengetahui seberapa besar variabel independen dapat menjelaskan variabel dependen. Hasil uji koefisien determinasi Tabel 4.3 diketahui bahwa nilai adjust $R$ Square (R2) adalah 0,517 atau 51,7\%. Ini berarti bahwa 51,7\% variabel kualitas audit dapat dijelaskan oleh variabel human capital dan spiritual capital. Sedangkan sisanya sebesar 48,3\% dijelaskan oleh variabel lain yang tidak dimasukkan dalam model penelitian ini.

Tabel 4.3 Hasil Uji Koefisien Determinasi

\begin{tabular}{|c|c|c|c|c|c|}
\hline Model & $\mathrm{R}$ & $\begin{array}{c}\mathrm{R} \\
\text { Square }\end{array}$ & $\begin{array}{c}\text { Adjusted } \\
\text { R. } \\
\text { Square }\end{array}$ & $\begin{array}{l}\text { Std. Error of } \\
\text { the } \\
\text { Estimate }\end{array}$ & $\begin{array}{l}\text { Durbin - } \\
\text { Watson }\end{array}$ \\
\hline & $.730^{a}$ & .533 & .517 & 2.929 & 2.0 \\
\hline
\end{tabular}

a. Predictors: (Constant), X1, X2,

b. Dependent Variable: Y

Sumber : Data Primer Diolah, 2019

\section{Hasil Uji Hipotesis}

Hasil Uji Secara Parsial (Uji t) dan Simultan (F)

Hasil pengujian pengaruh $\mathrm{X}_{1}$ (Human Capital) dan $\mathrm{X}_{2}$ (Spiritual Capital) terhadap Y (Kualitas Audit) adalah sebagai berikut:

1. Human Capital $\left(\mathrm{X}_{1}\right)$

Hasil pengujian hipotesis 1 human capital menunjukkan nilai $t_{\text {hitung }}$ sebesar 3,398 >

$\mathrm{t}_{\text {tabel }}$ 2,00247 dan memiliki nilai signifikansi sebesar 0,001 <0,05 serta koefisien korelasi memiliki arah positif sebesar 0,335 adalah berpengaruh signifikan dan positif terhadap kualitas audit. Dengan demikian maka hipotesis 1 diterima.

2. Spiritual Capital $\left(\mathrm{X}_{2}\right)$

Hasil pengujian hipotesis 2 spiritual capital menunjukkan nilai $t_{\text {hitung }}$ sebesar 4,842 $>t_{\text {tabel }} 2,00247$ dan memiliki nilai signifikansi sebesar $0,000<0,05$ serta koefisien korelasi memiliki arah positif sebesar 0,456 adalah berpengaruh signifikan dan positif terhadap kualitas audit. Dengan demikian maka hipotesis 2 diterima. Hal ini dapat dilihat pada Tabel 4.4 berikut.

Tabel 4.4 Hasil Uji Regresi Linear Berganda

\begin{tabular}{lccccc}
\multicolumn{7}{c}{$\begin{array}{c}\text { Unstandardized } \\
\text { Coefficients }\end{array}$} & $\begin{array}{l}\text { Standardized } \\
\text { Coefficients }\end{array}$ \\
Model & B & Std. Error & Beta & t & Sig. \\
\cline { 1 - 1 } 1 (Constant) & 17.098 & 4.508 & & 3.792 & .000
\end{tabular}


Jurnal Progres Ekonomi Pembangunan (JPEP)

Volume 4, Nomor 2, Tahun 2019

Page: $38-51$

http://ojs.uho.ac.id/index.php/JPEP

\section{TIDCID}

e-ISSN: 2052-5171

\begin{tabular}{llllll}
\hline $\mathrm{X} 1$ & & & & & \\
$\mathrm{X} 2$ & .335 & .098 & .348 & 3.398 & .001 \\
$\mathrm{D}$ & .456 & .094 & .496 & 4.842 & .000
\end{tabular}

a. Dependent Variable : Y

Sumber: Data Primer Diolah, 2019

3. Human Capital dan Spiritual Capital Secara Simultan Berpengaruh signifikan dan positif Terhadap Kualitas Audit. Hasil uji simultan terlihat bahwa F hitung $=33,059>\mathrm{F}$ tabel $=3,16$ dengan nilai signifikansi $0,000<0,05$. Hal ini berarti bahwa human capital $\left(\mathrm{X}_{1}\right)$ dan spiritual capital $\left(\mathrm{X}_{2}\right)$ secara simultan atau bersama-sama berpengaruh positif dan signifikan terhadap kualitas audit, dapat dilihat pada Tabel 4.5 berikut.

Tabel 4.5 Hasil Uji Hipotesis Secara Simultan (Uji F)

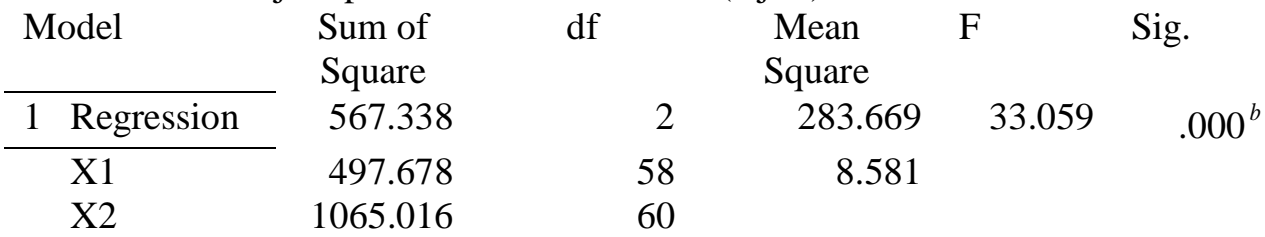

a. Dependent Variable: Y

b. Predictors: (Constant), X2, X1

Sumber: Data Primer Diolah, 2019

Adapun hasil pengujian diatas dapat digambarkan pada skema berikut.

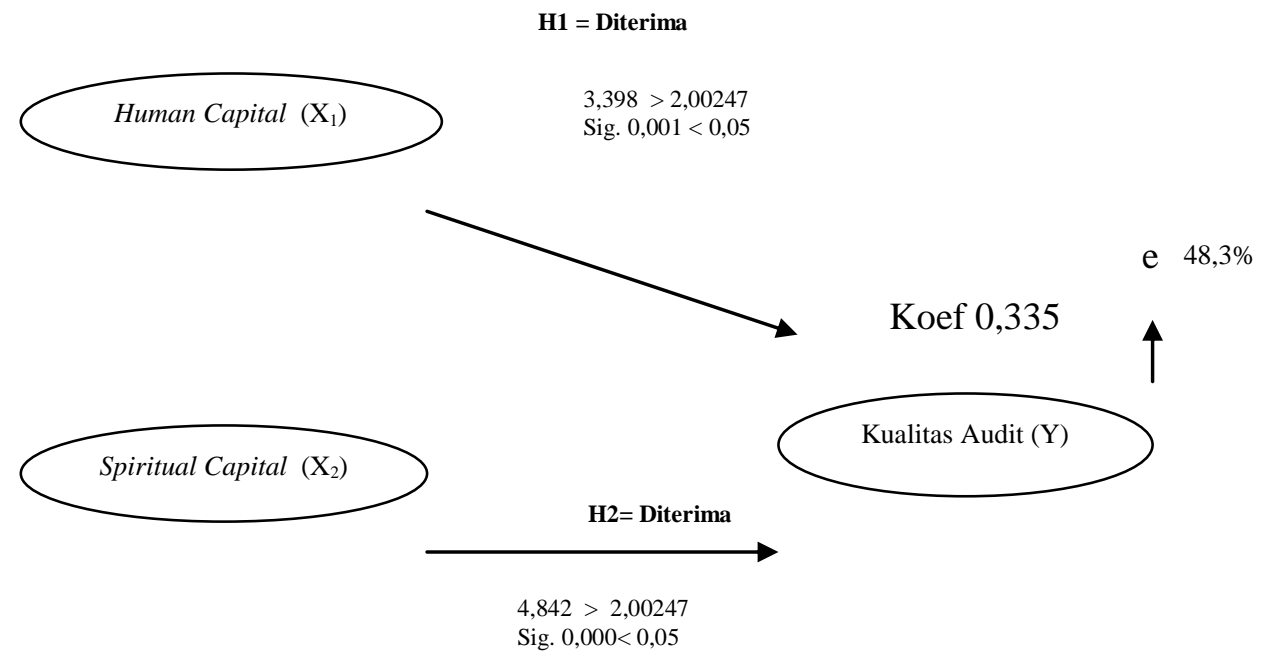

Gambar 4.1: Hasil Penelitian

\section{Pembahasan}

Pengaruh Human Capital terhadap Kualitas Audit.

Hasil pengujian hipotesis 1 (H1) menunjukkan bahwa human capital berpengaruh signifikan dan positif terhadap kualitas audit di BPK RI Perwakilan Provinsi Sulawesi Tenggara. Kondisi ini memperlihatkan bahwa semakin baik human capital yang dimiliki oleh seorang auditor maka kualitas audit yang dihasilkan pun semakin baik. Hasil analisis yang telah dilakukan menunjukkan bahwa human capital auditor mempunyai pengaruh signifikan dan positif terhadap kualitas audit.

Hasil analisis yang telah dilakukan menunjukkan persepsi responden mengenai human capital sangat baik. Proses analisis ketiga indikator yakni keahlian (pendidikan \& pengalaman), kompetensi dan komitmen organisasi (hubungan antar personal dengan organisasi) menunjukkan bahwa ketiga indikator tersebut mampu mendeskripsikan variabel human capital. Indikator keahlian (pendidikan \& pengalaman) 
Jurnal Progres Ekonomi Pembangunan (JPEP)

Volume 4, Nomor 2, Tahun 2019

Page: $38-51$

http://ojs.uho.ac.id/index.php/JPEP

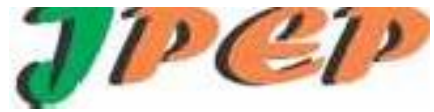

e-ISSN: 2052-5171

yaitu dengan banyaknya penugasan pemeriksaaan yang ditangani sangat membantu auditor dalam menemukan kesalahan yang terdapat pada laporan keuangan auditee. Banyaknya pelatihan yang dimiliki sangat membantu dalam memahami prosedur pemeriksaan dan jenis pemeriksaan yang akan dilakukan saat penugasan. Indikator kompetensi pun sangat wajib dimiliki oleh auditor di lingkungan BPK RI Perwakilan Provinsi Sulawesi Tenggara utamanya pengetahuan tentang standar yang berlaku terkait objek pemeriksaan yang sangat mendominasi kompetensi, kemudian rencana kerja dan syarat-syarat pekerjaan terkait objek pemeriksaan, serta beberapa skill lainnya yang sangat dibutuhkan saat melakukan penelusuran bukti-bukti dan informasi yang diperoleh auditor, yang mendukung dalam melaksanakan setiap penugasan pemeriksaan. Indikator hubungan antar personal dengan organisasi di BPK Perwakilan Provinsi Sulawesi Tenggara yang dimiliki oleh auditor berupa keterikatan professional atau hubungan kekeluargaan yang terjalin dengan cukup baik di lingkungan kerja ataupun dengan rekan kerjanya. Dengan kondisi yang dijelaskan diatas walaupun tingkat mutasi kerja yang terjadi lumayan tinggi bagi setiap auditor setelah mereka memiliki masa kerja 3 sampai 5 tahun dalam setiap perwakilan namun itu tidak menghalangi auditor untuk tetap bekerja secara professional dimanapun mereka ditempatkan dan ini menjadi poin yang masih harus ditingkatkan lagi kedepannya yakni komitmen auditor terhadap organisasinya. Mutasi ini terjadi disebabkan oleh beberapa pertimbangan salah satunya adalah objektifitas pemeriksaan (yaitu untuk menghindari auditee diperiksa oleh orang yang sama berkali-kali).

Hasil penelitian ini mengkonfirmasi penelitian Cheng et al (2009) yang menyatakan HC yang diperoleh dari pengalaman, pendidikan profesionalisme dan pendidikan profesi berkelanjutan berpengaruh positif terhadap kualitas audit pada KAP; Bouhawia (2015) dengan hasil penelitiannya juga menyatakan bahwa pengalaman, kompetensi dan komitmen organisasi berpengaruh positif terhadap kualitas audit pada KAP di Libya; Haeridistia et al (2019) hasil penelitiannya menemukan auditor yang berpengalaman memiliki pengetahuan yang luas dan struktur pemikiran yang lebih berkembang daripada auditor yang tidak berpengalaman; Riswan (2012) dalam penelitiannya juga menyatakan bahwa komitmen organisasi mempunyai pengaruh positif signifikan terhadap kualitas audit pada KAP di Bandar Lampung; dan selanjutnya dari semua hasil penelitian di atas dengan sangat jelas menggambarkan bahwa keahlian audit (pendidikan \& pengalaman), kompetensi dan hubungan antar personal dengan organisasi yang merupakan bagian yang tidak terpisahkan dari human capital pada penelitian ini berpengaruh positif signifikan terhadap kualitas hasil audit.

Hasil penelitian ini berbeda dengan hasil penelitian yang dilakukan oleh Carolita (2012) yang menyatakan bahwa kompetensi tidak memiliki pengaruh signifikan terhadap kualitas audit, namun pengalaman kerja dan komitmen organisasi berpengaruh secara signifikan terhadap kualitas audit; dan Deli (2015) dalam penelitiannya menyatakan bahwa pengalaman tidak berpengaruh terhadap kualitas audit pada KAP kota Medan. Sehingga disimpulkan bahwa kompetensi, pengalaman, dan komitmen organisasi (bagian dari human capital dalam penelitian ini) tidak berpengaruh terhadap kualitas hasil audit.

\section{Pengaruh Spiritual Capital terhadap Kualitas Audit.}

Hasil pengujian hipotesis 2 (H2) menunjukkan bahwa spiritual capital berpengaruh positif signifikan terhadap kualitas audit di BPK RI Perwakilan Provinsi Sulawesi Tenggara. Kondisi ini memperlihatkan bahwa semakin baik spiritual capital yang dimiliki oleh seorang auditor maka kualitas audit yang dihasilkan pun semakin baik. Hasil analisis yang telah dilakukan menunjukkan bahwa spiritual capital auditor mempunyai pengaruh positif signifikan terhadap kualitas audit. Jika seorang auditor memiliki spiritual capital yang baik maka ketenangan tersebut dapat diperoleh dengan mempererat hubungannya dengan Tuhan. Seorang auditor yang memiliki hubungan baik dengan Tuhannya maka tujuan dari bekerja tidak hanya untuk mencari materi semata, melainkan untuk beribadah kepada Tuhannya. Kejujuran merupakan suatu hal yang penting untuk dimiliki oleh auditor. Dengan memiliki spiritual capital, auditor dianggap mampu melakukan pekerjaannya dengan jujur. Jika auditor mampu menerapkan kejujuran pada tiap pekerjaan audit maka auditor tersebut mampu mempertahankan independensi dan objektifitasnya. Selanjutnya karena memiliki sikap kejujuran tersebut maka, auditor mampu menghindari perilakuperilaku menyimpang selama melakukan pekerjaan lapangan sehingga, opini yang dihasilkan bebas dari kepentingan pihak-pihak terkait. Auditor dengan kualitas spiritual capital yang baik akan cenderung 
Jurnal Progres Ekonomi Pembangunan (JPEP)

Volume 4, Nomor 2, Tahun 2019

Page: $38-51$

http://ojs.uho.ac.id/index.php/JPEP

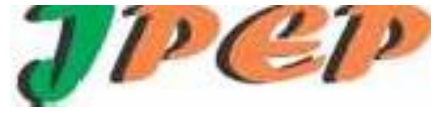

e-ISSN: 2052-5171

selalu taat pada aturan dan berusaha untuk tidak melawati batasan-batasan yang telah ditentukan. Dengan sikap yang demikian auditor tersebut akan berpegang teguh terhadap etika profesi yang berlaku sehingga terhindar dari perilaku menyimpang dalam melakukan penugasan audit.

Hasil penelitian ini mengkonfirmasi penelitian yang dilakukan oleh Nalsmosavi (2013) yang menyatakan spiritual capital mempengaruhi opini auditor yang berarti bahwa semakin baik spiritual capital yang dimiliki oleh seorang auditor maka kualitas audit yang dihasilkan juga semakin berkualitas sehingga bisa dikatakan bahwa spiritual capital berpengaruh signifikan terhadap kualitas audit; Sukmawati et al (2014) pada hasil penelitiannya menyatakan bahwa kecerdasan spiritual berpengaruh signifikan terhadap opini auditor; Januraga (2015) juga pada hasil penelitiannya menyatakan bahwa kecerdasan spiritual berpengaruh positif dan signifikan terhadap kualitas audit.

\section{KESIMPULAN DAN SARAN \\ Kesimpulan}

Berdasarkan hasil penelitian dan pembahasan tentang pengaruh human capital dan spiritual capital terhadap kualitas audit pada Badan Pemeriksa Keuangan Perwakilan Provinsi Sulawesi Tenggara maka dapat ditarik kesimpulan bahwa:

1. Human capital berpengaruh secara signifikan dan positif terhadap kualitas audit pada Badan Pemeriksa Keuangan Republik Indonesia Perwakilan Provinsi Sulawesi Tenggara.

2. Spiritual capital berpengaruh secara signifikan dan positif terhadap kualitas audit pada Badan Pemeriksa Keuangan Republik Indonesia Perwakilan Provinsi Sulawesi Tenggara.

\section{Saran Penelitian}

Berdasarkan hasil penelitian yang telah dilakukan dan keterbatasan dari penelitian ini, maka beberapa saranyang dapat disampaikan untuk penelitian yang akan datang adalah sebagaiberikut:

1. Saran untuk Pemeriksa Badan Pemeriksa Keuangan Republik Indonesia Perwakilan ProvinsiSulawesi Tenggara agar lebih meningkatkan kualitas audit mereka. Sehingga kualitas auditnya tetap terjaga dan opini yang dihasilkan benar-benar mencerminkan kondisi yang sebenarnya.

2. Beberapa variabel baru dapat ditambahkan dalam penelitian selanjutnyauntuk mendapatkan hasil prediksi yang berbeda.

\section{DAFTAR PUSTAKA}

Aisyah, Yana Dan Jaka Isgayarta. 2014. Analisis Pengaruh Human Capital Terhadap Kualitas Auditor (Studi Empiris Pada Bank Bri Kantor Inspeksi Semarang). Diponegoro Journal Of Accounting. Volume 3, Nomor 2, Tahun 2014, Halaman 1-10. ISSN (Online): 2337-3806

Agoes, Soekrisno. 2017. Auditing. Petunjuk Praktis Pemeriksaan Akuntan Oleh Akuntan Publik. Edisi Kelima, Buku 1, Jakarta: Salemba Empat

Algam, Ginrey Shandy. 2018. Hermeneutika Gadamerian Untuk Memahami Kualitas Audit

(Pemeriksaan Keuangan) BPK RI. Jurnal Akuntansi Aktual : Vol. 5, No. 1, Hlm. 31-45 E-ISSN: 25801015; P-ISSN: 20879695

Arens, Alvin A., Randal J. Elder and Mark S. Beasley. 2010. Auditing \& Assurance Services An Integrated Approach. 13th Edition. New Jersey: Prentice Hall.

Badan Pemeriksa Keuangan. 2019. "Ikthisar Hasil Pemeriksaan Semester 1 Tahun 2018"

Baron A.R And Greenberg J. 2000. Behaviour In Organisations, Prentice Hall, 8, 188-215.

Berger, P. L., And Helfiner, R. W. 2003. Spiritual Capital In Comparative Perspective. Paper Presented

At The Spiritual Capital Planning Meeting. 10-11 October, Cambridge: Massachusetts

Berle, A dan G. Means. 1932. The Modern Corporation and Private Property. New York, Macmillan.

Beritaklik.Com. Kado Perdana Ali Mazi Dari Menkeu. Tersedia Di:https://www.beritaklick.Com/Headline/Kado-Perdana-Ali-Mazi-Dari-Menkeu/

Bonner, E., And Lewis, B. L. 1990. Determinants Of Auditor Expertise. Journal Of Accounting Research, $28,1-20$.

Bontis, Nick. 1998. Intellectual Capital: An Exploratory Study That Develops Measures And Models. 
Jurnal Progres Ekonomi Pembangunan (JPEP)

Volume 4, Nomor 2, Tahun 2019

Page: $38-51$

http://ojs.uho.ac.id/index.php/JPEP

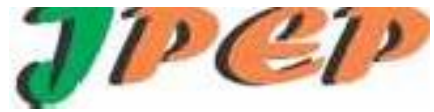

e-ISSN: 2052-5171

Management Decision, Vol.36 ISS: 2, pp.63-76.

Bontis, Nick. 2000. Assessing Knowledge Assets: A Review of the Models Used to Measure Intellectual Capital.

Bouhawia, M. S., G. Irianto., Dan Z. Baridwan. 2015. The Effect Of Working Experience, Integrity, Competence, And Organizational Commitment On Audit Quality (Survey State Owned Companies In Libya). e-ISSN: 2321-5933, p-ISSN: 2321-5925.Volume 6, Issue 4. Ver. II (Jul. - Aug. 2015), PP 6067 .www.iosrjournals.org

Boynton, William C., Raymond N. Johnson, and Walter G. Kell. 2003. Modern Auditing 2, 7th Edition. Jakarta: Erlangga

BPK RI. 2011. Siaran Pers: Opini WTP Tidak Menjamin Tidak Ada Korupsi. Badan Pemeriksa Keuangan Republik Indonesia. Tersedia Di: http://www. bpk.go.id/news/opini-wtp-tidak menjamintidak-ada-korupsi.

BPK RI. 2017. Siaran Pers: Opini WTP Dan Korupsi. Tersedia Di: http://www.bpk.go.id/news/opini-wtpdan-korupsi.

BPK RI. 2019. Siaran Pers: Knowledge Transfer Forum "IT Audit Dalam Audit Laporan Keuangan". Tersedia di: http://kendari.bpk.go.id/?p=6149

Carolita, Metha Kartika. 2012. Pengaruh Pengalaman Kerja, Independensi, Objektifitas, Integritas, Kompetensi, Dan Komitmen Organisasi Terhadap Kualitas Hasil Audit. (Studi Pada Kantor Akuntan Publik Di Semarang). Diponegoro Journal Of Accounting Volume 1, Nomor 2, Tahun 2012, Halaman 1-11. http://ejournal-s1.undip.ac.id/index.php/accounting

Carpenter, T., Durtschi, C., And Gaynor, L. M. 2002. The Role Of Experience In Professional Skepticism, Knowledge Acquisition, And Fraud Detection. Accounting Workshop Florida State University, 1-28.

Chen, Jin, Zhaohui Zhu, Hong Yuan Xie. 2004. Measuring intellectual capital: a new model and empirical study. Journal of Intellectual Capital Vol. 5 No. 1, 2004 pp. 195-212. DOI 10.1108/14691930410513003

Cheng, Yi-Pei Liu Chu-Yang Chien. 2009. "The association between auditor quality and human capital". Managerial Auditing Journal, Vol. 24 Iss 6 pp. 523 - 541

Covey, S.R. 1992. Principal Centred Leadership. New York: First Fireside.

De Angelo, L. E. 1981. Auditor Size And Audit Quality. Journal Of Accounting And Economics. 3 (1981): 183-199

Deli, Leni. 2015. Faktor-Faktor Yang Mempengaruhi Kualitas Audit Dengan Etika Auditor Sebagai Moderating Variabel. Jurnal Riset Akuntansi Dan Bisnis. Volume 15 No.1 /Maret 2015

Edvinsson, L. and M. Malone. 1997. Intellectual Capital : Realizing Your Company's True Value by Finding its Hidden Brainpower. New York: HarperCollins,

Francis, J.R. 2004. What Do We Know About Audit Quality? British Accounting Review, 36(4), pp.345-368.

Ghozali, Imam. 2018. Aplikasi Analisis Multivariate dengan Program IBM SPSS 25. Badan Penerbit: -UNDIP. Semarang

Howard, S. 2002. A Spiritual Perspective On Learning In The Workplace. Journal Of Managerial Psychology, 17,230-242

International Auditing And Assurance Standards Board. 2013. "A Framework For Audit Quality". International Federation Of Accountants.

Ismail, M.B. 2005. The Influence Ofintellectual Capital On The Performance Of Telekom Malaysia. Phd Dissertasion. University Teknology Malaysia.

Januraga, Budiartha. 2015. Pengaruh Teknik Audit Berbantuan Komputer, Kompetensi Auditor, Dan Kecerdasan Spiritual Pada Kualitas Audit BPK Bali. E-Jurnal Akuntansi Universitas Udayana. Vol.13.3 Desember (2015): 1137-1163 .ISSN: 2303-1018

Jensen, M. C and Meckling, W.H. 1976. Theory of the Firm: Managerial Behavior, Agency Costs and Ownership Structure. Journal of Financial Economics, Oktober, 1976, V. 3, No. 4, pp. 305-360. Avalaible from: http://papers.ssrn.com.

Kalbers, Lawrence P., And Timothy J. Forgarty. 1995. Profesional And Its Consequeences: A Study Of 
Jurnal Progres Ekonomi Pembangunan (JPEP)

Volume 4, Nomor 2, Tahun 2019

Page: $38-51$

http://ojs.uho.ac.id/index.php/JPEP

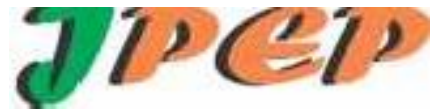

e-ISSN: 2052-5171

Internal Auditors. Auditing.Journal Of Practice And Theory, 14(1), 64-86.

Khavari. 2000. The Art Of Happines (Mencapai Kebahagiaan Dalam Setiap Keadaan). Jakarta: Mizan Pustaka

Kiswara, Dandy Evan.,Iswajuni, Cintya Handayani, Soegeng Soetedjo. 2018. Meta Analisis: Faktor-

Faktor Yang Mempengaruhi Kualitas Audit Pada Aparat Pengawasan Internal Pemerintah (APIP)

Di Indonesia. Jurnal Akuntansi, Ekonomi dan Manajemen Bisnis. Vol. 6 No. 1, Juli 2018, 54-66 . EISSN : 2548-9836

Libby, R, And Frederick, D. M. 1990. Experience And The Ability To Explain Audit Findings. Journal Of Accounting Research, 28(2),348 -367.

Liu, A. 2008. Measuring Spiritual Capital As A Latent Variable. (Online Article): http://www.researchmethod.org/measuringspcapital.pdf

Mardiasmo. 2006. Perwujudan Transparansi dan Akuntabilitas Publik Melalui Akuntansi Sektor Publik : Suatu Sarana Good Governance. Jurnal Akuntansi Pemerintahan, 2:1.(1-17).

Mohtar, Shahimi Et Al. 2015. Intellectual Capital And Its Major Components. Journal Of Technology And Operations Management 10(1), 15-21 (2015)

Nahapiet, J. \& Ghoshal, S. 1998. Social Capital, Intellectual Capital And The Organisational Advantage. Academy of Management Review, 23:242-266.

Naslmosavi, Seyedhossein, Saudah Sofian And Maisarah Binti Mohamed Saat. 2013. Intellectual Capital Components And Independent Auditor's Opinion: A Review On Past Studies. Middle-East Journal Of Scientific Research 15 (4): 500-510, 2013

Naslmosavi, Seyedhossein, Agha Jahanzeb. 2017. The Effect Of Spiritual Capital Of Individuals On Independent Auditor's Opinion: Evidences From Iranian Auditors. Asian J Bus Ethics (2017) 6:131152 DOI 10.1007/s13520-016-0069-z

Peraturan BPK No.4 Tahun 2010 Tentang Jabatan Fungsional Pemeriksa pada Badan Pemeriksa Keuangan.

Peraturan BPK No.1 Tahun 2017 Tentang Standar Pemeriksaan Keuangan Negara.

Peraturan BPK No.2 Tahun 2017 Tentang Pemantauan Pelaksanaan Tindak Lanjut Rekomendasi Hasil Pemeriksaan Badan Pemeriksa Keuangan.

Peraturan BPK No.1 Tahun 2019 Tentang Organisasi dan Tata Kerja Pelaksana Badan Pemeriksa Keuangan

Rahmatia. Kamba, Nasrullah Dali dan Mulyati Akib. 2019. Pengaruh Human Capital, Structural Capital, dan Spiritual Capital Terhadap Kualitas Audit Pada Badan Pemeriksa Keuangan Republik Indonesia Perwakilan Provinsi Sulawesi Tenggara. Tesis. Kendari: Program Studi Magister Ilmu Ekonomi Konsenttrasi Akuntansi Universitas Haluoleo.

Riswan. 2012. Pengaruh Independensi dan Komitmen Organisasi Terhadap Kualitas Audit (Studi pada Kantor Akuntan Publik di Bandar Lampung, Bandung, dan Jakarta). Jurnal Manajemen dan Bisnis Vol. 2 No. 2 April 2012: 124-150

Sawarjuwono, Tjiptohadi. 2003. Intellectual Capital: Perlakuan, Pengukuran Dan Pelaporan (Sebuah Library Research). Jurnal Akuntansi \& Keuangan Vol. 5, No. 1, Mei 2003: 35 - 57

Simorangkir, Ferina. 2012. Hubungan Antara Human Capital Dan Kualitas Auditor Di Badan Pemeriksa Keuangan (BPK) Provinsi Sumatera Selatan. Jurnal Manajemen Dan Bisnis Sriwijaya Vol.10 No.19 Juni 2012

Solimun, Adji Achmad R.F. Samingun Handoyo, 2017. Penyusunan Instrumen Penelitian Transformasi Skor menjadi Skala Pendekatan MSI, SRS \& Rasch Model. Jurusan Matematika FMIPA UB Tanggal 18-19 Februari 2017.

SPKN (Standar Pemeriksaan Keuangan Negara). Peraturan BPK RI No. 01 Tahun 2017. Ditama Binbangkum BPK RI.

Stewart, T.A. 1997. Intellectual Capital. London: Nicholas Brealey Publishing.

Stewart, T.A. 1997. Intellectual Capital:The New Wealth of Organizations. London, United Kingdom: Nicholas Brealey Publishing

Sugiyono. 2017. Metode Penelitian Kombinasi (Mixed Methods). Bandung: Alfabeta. 
Jurnal Progres Ekonomi Pembangunan (JPEP)

Volume 4, Nomor 2, Tahun 2019

Page: $38-51$

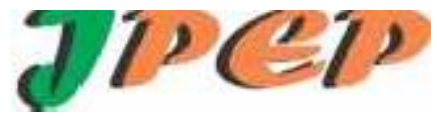

http://ojs.uho.ac.id/index.php/JPEP

e-ISSN: 2052-5171

Sugeng, ND, Imam. 2002. Mengukur dan Mengelola Intellectual Capital. Jurnal Ekonomi dan Bisnis Indonesia (JEBI), Fakultas Ekonomi UGM, Volume 15 No. 2

Tandiontong, Mathius. 2015. Kualitas Audit dan Pengukurannya. Bandung

Torres, M.R. Martinez. 2006. A Procedure to Design a Structural and Measurement Model of Intellectual Capital: an Exploratory Study. Information and Management, Vol.43, p: 617-626

Tuanakotta, Theodorus M. 2011. Berpikir Kritis dalam Auditing. Jakarta. Salemba Empat.

Ulrich, D. 1998. "Intellectual Capital= Competence $x$ Commitment", Sloan management review, 39(2), 15.

Undang-Undang No. 17 Tahun 2003 Tentang Keuangan Negara

Undang-Undang No. 15 Tahun 2004 Tentang Pemeriksaan Tanggung Jawab Dan Pengelolaan Keuangan Negara

Undang-Undang Republik Indonesia Nomor 15 Tahun 2006 tentang Badan Pemeriksa Keuangan

Undang-Undang No. 23 Tahun 2014 Tentang Pemerintah Daerah

Zimmerman, Jerold, L dan Watts, Ross.L. 1983. Agency Problems, Auditing, and the Theory of the Firm: Some Evidence. The Journal of Law and Economics - February 1983 DOI: 10.1086/467051 - Source: RePEc

Zohar, Danah Dan Marshal, Ian. 2002. SQ, Memanfaatkan Kecerdasan Spiritual Dalam Berfikir Integralistik Dan Holistik Untuk Memaknai Kehidupan. Bandung. Mizan 